\title{
Reducing Compounds and the Growth of Phytophthora infestans
}

\author{
By D. W. HOLLOMON \\ Botany Department, University of Hull
}

(Received 8 March 1966)

\begin{abstract}
SUMMARY
An investigation into the effect of light on the growth of Phytophthora infestans revealed that whereas exposure to light caused diminished growth on pea medium, growth on several other media was not decreased. This diminished growth was an indirect effect of light caused by an alteration of the medium. All the $\boldsymbol{P}$. infestans tested reacted similarly, but most other fungi examined were unaffected. Germination of zoospores of $\boldsymbol{P}$. infestans appeared to be especially sensitive. This inhibitory effect was not removed by heat and peroxides were not, therefore, considered as the immediate cause of the inhibition. Nevertheless, following exposure to light, peroxide formation and the appearance of the inhibitory effect were closely associated. Addition of several reducing compounds to pea medium overcame the effect of exposure to light on zoospore germination. Mycelial growth was also improved by similar additions to a defined medium. This was particularly marked following the addition of glutathione $\left(10^{-3} \mathrm{M}\right)$ and $\mathrm{L}$-ascorbic acid ( $1.0 \mathrm{~g} . / 1$.$) . The decrease in reducing potential during illumination might, in$ the light of experiments conducted with defined media, explain the observed effects of illumination.
\end{abstract}

\section{INTRODUCTION}

Hirst (1953) detected a marked diurnal periodicity in the occurrence of Phytophthora infestans in the atmosphere and suggested that this diurnal fluctuation depended on hygroscopic changes during drying to liberate sporangia. This suggestion was in part based on the report by Crosier (1934) that the sporulation process in $\boldsymbol{P}$. infestans was unaffected by light. The peak spore concentration of $\boldsymbol{P}$. infestans spores occurred shortly before noon and coincided with a similar peak in the numbers of Pseudoperonospore humuli (hop downy mildew) spores (Hirst, 1953). However, with hop downy mildew, Yarwood (1937) suggested that the diurnal cycle of sporulation was basically dependent on the alteration of light and darkness. In view of these observations, and of the close taxonomic relation between the downy mildews and $\boldsymbol{P}$. infestans, it was considered of interest to investigate the effect of light on the development of $\boldsymbol{P}$. infestans. As compared to work with the downy mildews, such an investigation offers the advantage that $\boldsymbol{P}$. infestans can be cultured in vitro.

\section{METHODS}

Media. Pea medium was used throughout. It was obtained by macerating $160 \mathrm{~g}$. 'Birds Eye' frozen peas in 1 l. water for $3 \mathrm{~min}$. in a Waring Blendor, and filtering the homogenate through muslin. When required as a solid medium, $2 \%(w / v)$ agar 
was then added to the liquid. Where a defined medium was used, $0.05 \%(\mathrm{w} / \mathrm{v})$ $\mathrm{L}$ - $\beta$-asparagine and $\mathbf{0 . 2} \%(\mathrm{w} / \mathrm{v})$ vitamin-free Casamino acids were added to the basal medium described by Hall (1959). All the media were autoclaved at $115^{\circ}$ for $10 \mathrm{~min}$.

Conditions of illumination. Solidified medium was exposed to light in 6 in. $\times \frac{5}{8}$ in. Pyrex test tubes, and liquid medium in $8 \mathrm{oz}$. soft-glass medicine bottles (United Glass Blowers Ltd.). These bottles were laid flat, providing a layer of medium approximately $\frac{1}{4}$ in. deep. The cultures were placed in a light-proof chamber $2 \mathrm{ft}$. 6 in. beneath two fluorescent lamps (Osram 40 W. Daylight $M C F / U$ ), at which level the light intensity was 130 f.c. These lamps provided light of wavelengths between $3900 \AA$ and $74,00 \AA$, and little, if any, ultraviolet radiation was emitted. A temperature of $21^{\circ} \pm 1^{\circ}$ was maintained within the chamber by a fan which circulated air beneath the lamps. To obtain conditions of darkness, tubes and bottles were covered with aluminium foil, although this decreased the temperature in the cultures by $0.8^{\circ}$ compared with the temperature within exposed cultures.

Inoculum. Mycelial discs were cut from the edges of the cultures grown on the basal medium described by Hall (1959), to which only $0.05 \%(w / v) L-\beta$-asparagine was added. To obtain zoospores, sporangia were washed with water from cultures on pea medium slopes which had been similarly treated $48 \mathrm{hr}$ earlier. When kept at $10^{\circ}$ for $3 \mathrm{hr}$, zoospores readily emerged from these sporangia.

Measurements. All cultures were incubated in darkness at $12^{\circ}$. Measurements were made after incubation only for 6 days when pea medium was used, but after 14 days when the defined medium was used. Colony length was measured in all treatments inoculated with mycelial discs, and in treatments inoculated with zoospores the degree of germination was assessed on a scale in which 5 (the normal maximum) represented the resulting mycelial growth on unilluminated pea medium at 6 days.

\section{RESULTS}

The effect of pre-exposure of organic media on the growth of Phytophthora infestans

A preliminary experiment showed that continuous illumination decreased the growth of Phytophthora infestans when grown on pea medium, but not when grown on defined medium. To investigate whether this inhibition on illuminated pea medium was a direct or indirect effect of light, tubes of both pea and defined media were exposed to light before inoculation for periods of 144, 72, 24 and $0 \mathrm{hr}$, and then inoculated with mycelial discs of isolate $\mathrm{D}$ (see Fig. 1).

Illumination of the defined medium before inoculation had little effect on growth (see Fig. 1), but illumination of the pea medium for only $24 \mathrm{hr}$ before inoculation decreased colony length; longer periods of illumination did not cause a greater decrease of growth. The decreased growth of $\boldsymbol{P}$. infestans on illuminated pea medium therefore appeared to be an indirect effect of light caused by an alteration of the medium.

To determine if exposure of other organic media to light also decreased the growth of $\boldsymbol{P h y t o p h t h o r a ~ i n f e s t a n s , ~ t u b e s ~ o f ~ m e d i a ~ p r e p a r e d ~ f r o m ~ v e g e t a b l e ~ j u i c e , ~ f r o z e n ~ b e a n s , ~}$ oatmeal or dried peas, were exposed to continuous light for 3 days before inoculation with mycelial discs. Although the growth rate on all these media was less than half the rate on pea medium, pre-illumination of all four media did not affect growth, 


\section{Reducing compounds and growth of Phytophthora infestans 317}

which indicated that the light-sensitive factor present in frozen peas was not present in other organic material, including dried peas.

\section{Effect of pre-exposure on the growth of Phytophthora infestans isolates}

In previous experiments only Phytophthora infestans isolate $\mathbf{D}$ was used, but to ensure that the results obtained were not atypical, seven other isolates (Table 1) were tested for their response to pea medium pre-illuminated for $\mathbf{2 4} \mathrm{hr}$. A comparison between isolates was possible after measuring colony length. The results in Table 1 demonstrate that pre-illumination of the pea medium restricted the growth of all the isolates tested, although the degree of inhibition varied between isolates.

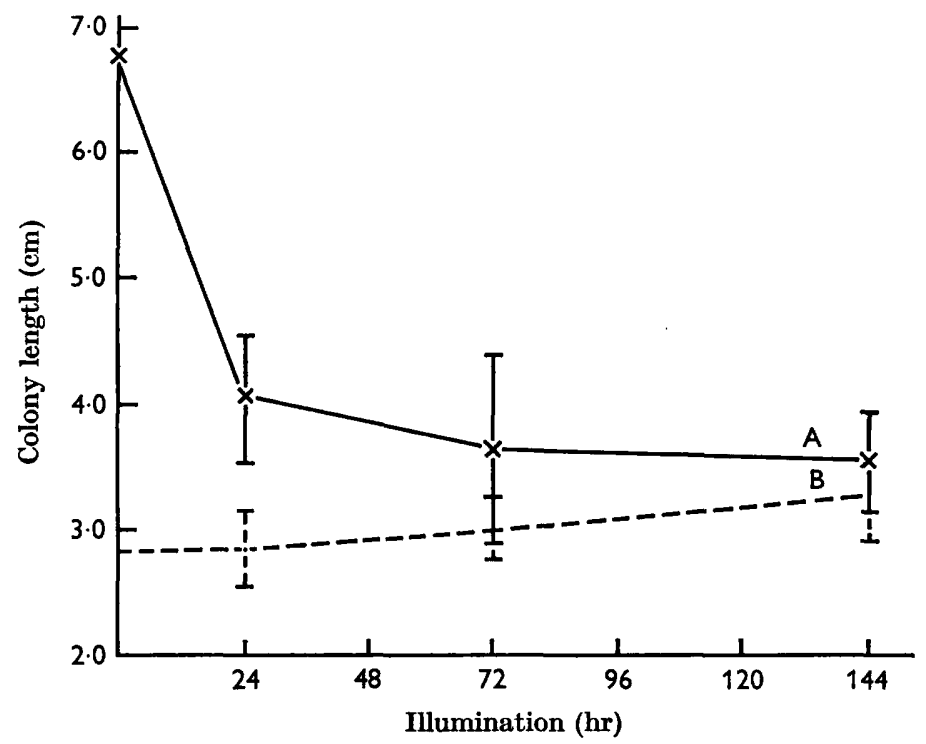

Fig. 1. Effect on the growth of Phytophthora infestans of media illuminated before inoculation for periods up to $144 \mathrm{hr}$. A, Pea medium; B, defined medium.

Table 1. Response of eight isolates of Phytophthora infestans to illuminated pea medium.

\begin{tabular}{|c|c|c|c|c|c|}
\hline Isolate & $\begin{array}{c}\text { Age } \\
\text { (years) }\end{array}$ & $\begin{array}{l}\text { Potato } \\
\text { variety }\end{array}$ & $\begin{array}{c}\text { Non- } \\
\text { illuminated }\end{array}$ & Illuminated & $\begin{array}{c}\% \\
\text { inhibition }\end{array}$ \\
\hline $\mathbf{A}$ & 6 & Unknown & $40 \cdot 50^{*}$ & $31 \cdot 75^{*}$ & 22 \\
\hline $\mathbf{B}$ & 4 & Unknown & $49 \cdot 75$ & $31 \cdot 00$ & 38 \\
\hline $\mathbf{c}$ & 2 & $\begin{array}{l}\text { Pentland } \\
\text { Beauty }\end{array}$ & $51 \cdot 00$ & $37 \cdot 50$ & 27 \\
\hline $\mathbf{D}$ & 2 & Golden Wonder & $47 \cdot 75$ & $32 \cdot 25$ & 33 \\
\hline $\mathbf{E}$ & 1 & Majestic & $39 \cdot 25$ & $22 \cdot 75$ & 41 \\
\hline $\mathbf{F}$ & $\mathbf{1}$ & Majestic & $32 \cdot 25$ & $0 \cdot 00$ & 100 \\
\hline G & 0 & King Edward & $51 \cdot 75$ & $32 \cdot 25$ & 38 \\
\hline H & 0 & Orion & $52 \cdot 00$ & $32 \cdot 00$ & 39 \\
\hline
\end{tabular}

L.S.D. two treatment totals. $P<0.001=6.75$.

* Total colony length in cm., from eight replicates. 


\section{Sensitivity of various other fungi}

To determine whether the growth of other fungi was inhibited by illuminated pea medium, the response of several fungi was tested on illuminated medium which had been re-autoclaved before inoculation to destroy any peroxides present (see below). Only Phytophthora palmivora was inhibited by illuminated pea medium; growth of Acremoniella sp., Alternaria tenuis, Botrytis cinerea, Fusarium sp., Phytophthora cryptogea, $P$. heveae and Pythium sp. remained unaltered by exposure of the medium to light.

\section{Influence of inoculum source on the inhibitory effect of illuminated pea medium}

To investigate the effect of the inoculum on the inhibitory effect of illuminated medium, mycelial discs of Phytophthora infestans isolate $\mathrm{D}$ and two zoospore concentrations were inoculated into tubes of illuminated and non-illuminated pea medium. The results are shown in $\mathbf{P l}$. 1, fig. 1 . When zoospores were used as inoculum, the inhibitory effect was especially pronounced, largely because few spores germinated on illuminated medium. Zoospore germination appeared, therefore, to provide a more sensitive measure of the inhibitory effect of illuminated pea medium.

\section{Effect of autoclaving on the inhibition caused by illuminated pea medium}

Exposure of organic matter to light causes oxidation by processes which have been discussed in a series of papers edited by Lundberg (1961). In autoclaved pea medium this oxidation is non-enzymic and might result in the formation of peroxides. A marked similarity between the inhibition caused by the addition of hydrogen peroxide to organic media and the inhibition caused by ultraviolet and visible light was reported by both Wyss, Bennett Clark, Hass \& Stone (1948) and Weinhold $\&$ Hendrix (1963). If the inhibitory effect of illuminated pea medium was caused by thermolabile peroxides, re-autoclaving illuminated medium might be expected to remove this inhibition.

Mycelial discs of Phytophthora infestans isolate $\mathbf{D}$ were inoculated into tubes of pea medium which had received one of the following treatments : $(a)$ Tubes illuminated for $24 \mathrm{hr}$ and re-autoclaved $\left(115^{\circ}\right.$ for $10 \mathrm{~min}$.). (b) Tubes illuminated for $24 \mathrm{hr}$ but not re-autoclaved. (c) Tubes not illuminated but re-autoclaved before inoculation. $(d)$ Tubes not illuminated and not re-autoclaved (control).

An analysis of colony length after incubation for 6 days is given in Table 2. This experiment not only showed the effect of illumination, but also showed that reautoclaving both illuminated and non-illuminated media decreased growth. The nonsignificance of the interaction term suggested, however, that the inhibitory effect was unaltered by reheating and that peroxides did not directly cause this inhibition; it is possible that peroxides may in some way have been protected by the medium.

The nature of the alteration caused by the exposure of pea medium to light

The presence of peroxides in pea medium may cause the oxidation of metabolites required for normal growth by Phytophthora infestans, in which case peroxide formation might be associated with the appearance of the inhibitory effect following illumination. For this reason peroxide concentration and zoospore germination 


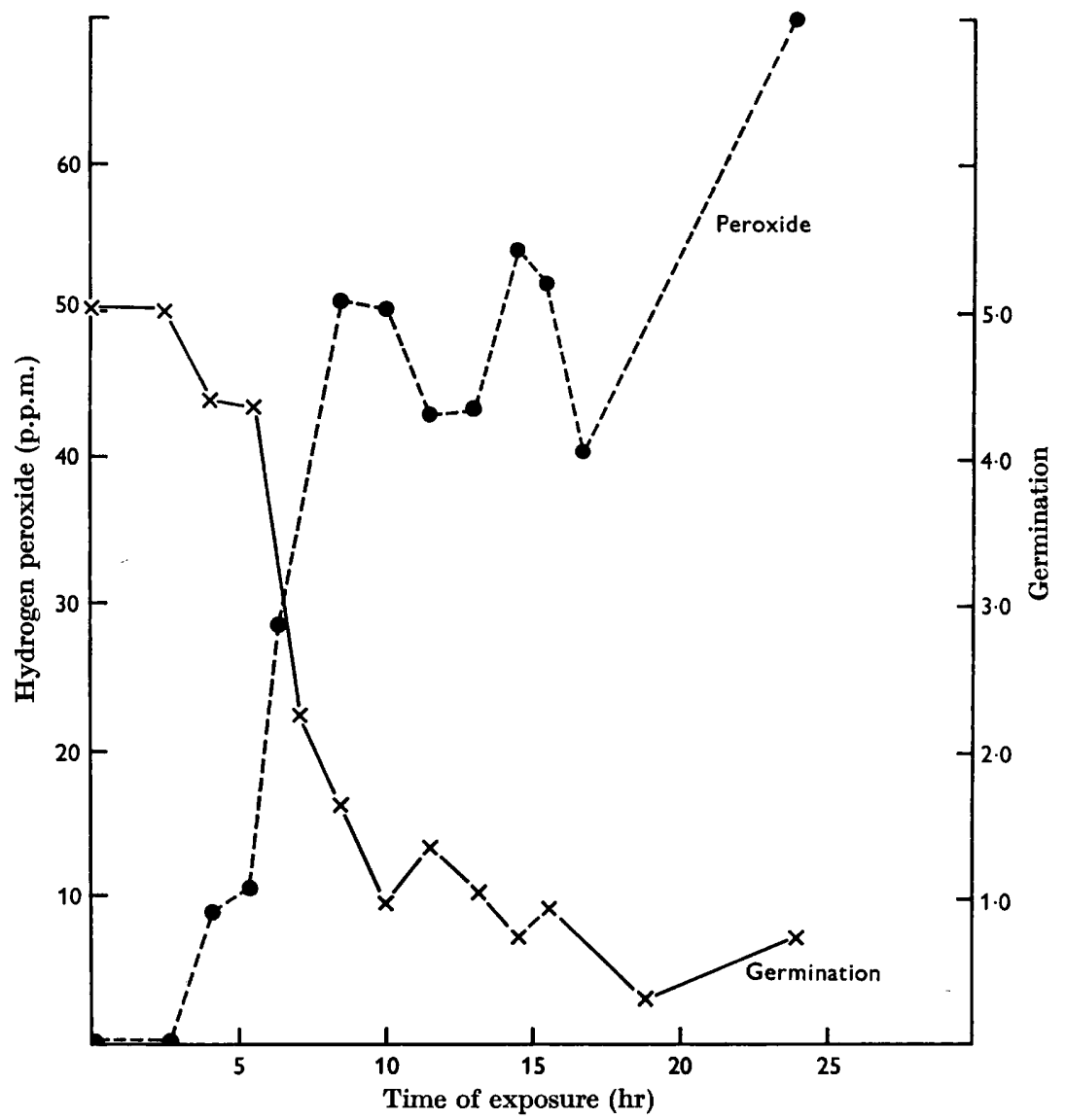

Fig. 2. The effect of up to $30 \mathrm{hr}$ illumination of pea liquid on peroxide formation and zoospore germination. Peroxide concentration is expressed in terms of p.p.m. (v/v) hydrogen peroxide, and germination is assessed on a 0-5 scale.

Table 2. Analysis of variance of colony length showing the effect of heat on the inhibition caused by illuminated pea medium

$$
\text { Source of variation }
$$

A. Re-autoclaving vs. not re-autoclaved

B. Illuminated vs, non-

illuminated

C. Interaction re-autoclaving $\times$ illumination

Error

\section{$\mathbf{N}$}$$
1
$$

1

1

24
M.s.

$0 \cdot 4,2$

$5 \cdot 85$

$\mathbf{0} \cdot \mathbf{1 0}$

$0 \cdot 03$
v.R.

$14 \cdot 00$

$195 \cdot 00$

3.33

N.S.

were measured for liquid pea medium at intervals of illumination for up to $30 \mathrm{hr}$. Peroxide concentration was estimated by a technique based on that described by Koch, Stern \& Ferrari (1958). A sample (0.25 ml.) of the illuminated pea liquid, $20 \mathrm{ml} . \mathbf{9 0} \%$ ethanol, $0.2 \mathrm{ml}$. conc. $\mathrm{HCl}$, and $0.05 \mathrm{ml} .5 \%(\mathrm{w} / \mathrm{v})$ ferrous ammonium 
sulphate in $3 \% \mathrm{HCl}$ were shaken together for $30 \mathrm{sec} ., 1.0 \mathrm{ml} .20 \%(\mathrm{w} / \mathrm{v})$ ammonium thiocyanate was then added, and after $3 \mathrm{~min}$. the extinction of the solution at $480 \mathrm{~m} \mu$ was measured, using a Beckman S.P.600 spectrophotometer. The extinction produced by the sample was compared with that produced by the same volume of liquid pea medium withdrawn at the same time but autoclaved at $105^{\circ}$ for $5 \mathrm{~min}$. The difference in extinction at $480 \mathrm{~m} \mu\left(\boldsymbol{E}_{480}\right)$ between the sample and the autoclaved blank was taken as a measure of the peroxide present in the sample, and expressed in terms of p.p.m. hydrogen peroxide by reference to a standard graph of $\boldsymbol{E}_{480}$ against hydrogen peroxide.

There was a 4-hr period before any peroxide was detected; thereafter the peroxide concentration rapidly increased, reaching 50 p.p.m. after 10-hr illumination (Fig. 2). With longer illumination times the concentration of peroxide remained fairly constant, and in another experiment a peroxide concentration equivalent to 50-60 p.p.m. hydrogen peroxide was maintained for at least $144 \mathrm{hr}$.

The liquid pea medium not required for each peroxide determination was used to prepare tubes of solid media. Each tube was inoculated with a loopful of zoospore suspension of Phytophthora infestans isolate $\mathbf{F}$, already shown to be extremely sensitive to illuminated pea medium. A small inhibitory effect on germination was observed after only 4-hr illumination (Fig. 2), and the degree of germination then declined rapidly, the inhibitory effect reaching a maximum after 10-hr illumination. The inhibitory effect on germination appeared, therefore, after between 5 - and 10-hr illumination and its appearance coincided with a rapid increase in peroxide concentration.

\section{The addition of reducing compounds to pea medium}

In addition to the formation of peroxides, other chemical changes are likely following the irradiation of organic matter. Arnow (1936) discussed the effects of u.v. irradiation on proteins and amino acids, and suggested that several amino acids may be altered on exposure to sunlight. Sulphydryl (-SH) groups may be oxidized by u.v. irradiation (Woodward, 1933).

If the inhibitory effect of illuminated pea medium were caused by the oxidation of substances within the medium, then the addition of reducing substances might possibly overcome the effect of illumination. Therefore, the compounds listed in Table 3 were added to liquid pea medium before, or after, it was exposed to light for $48 \mathrm{hr}$. All media were adjusted to $\mathrm{pH} 6.8$ before autoclaving and solidified with agar in sloped tubes. Each tube was then inoculated with a loopful of zoospore suspension $\left(10^{5}\right.$ zoospores/ml.). When germination was assessed the scale had to be extended beyond 5 because, in certain cases, it was better than that on the non-illuminated pea medium control.

L-Ascorbic acid, L-cysteine $\mathrm{HCl}$, and thioglycollic (mercapto-acetic) acid not only prevented the inhibitory effect when added to the liquid before illumination, but actually improved germination as compared with that on the non-illuminated control (Table 3). All three compounds also overcame the effect of exposure when added to the liquid after illumination.

When added before exposure, glutathione partially overcame the inhibitory effect, but DL-alanine, L-cystine, DL-methionine and glycollic acid were ineffective no matter when added to the liquid. 
Table 3. Zoospore germination following the addition of several compounds to pea medium before, and after, 48-hr illumination

\begin{tabular}{|c|c|c|c|c|}
\hline \multirow[b]{2}{*}{ Compound } & \multirow[b]{2}{*}{ Formula } & \multirow[b]{2}{*}{ Cone. (M) } & \multicolumn{2}{|c|}{ Germination } \\
\hline & & & $\begin{array}{l}\text { Added before } \\
\text { illumination }\end{array}$ & $\begin{array}{l}\text { Added after } \\
\text { illumination }\end{array}$ \\
\hline Thioglycollic acid & $\mathrm{SH} . \mathrm{CH}_{\mathbf{2}} \cdot \mathrm{COOH}$ & $10^{-8}$ & $10 \cdot 0 \pm 0.00$ & $8 \cdot 00 \pm 0 \cdot 00$ \\
\hline Glycollic acid & $\mathrm{OH} . \mathrm{CH}_{2} \cdot \mathrm{COOH}$ & $10^{-3}$ & $0.13 \pm 0.08$ & $0 \cdot 26 \pm 0 \cdot 17$ \\
\hline $\begin{array}{l}\text { L-Cysteine } \\
\text { hydrochloride }\end{array}$ & $\begin{array}{c}\mathrm{SH} . \mathrm{CH}_{2} \cdot \mathrm{CH} \cdot \mathrm{NH}_{2} \\
\left.\right|_{\mathrm{COO} . \mathrm{HCl}}\end{array}$ & $10^{-3}$ & $5 \cdot 70 \pm 2 \cdot 01$ & $4 \cdot 05 \pm 2 \cdot 31$ \\
\hline DL-Alanine & $\mathrm{CH}_{3} \cdot \mathrm{CH} \cdot \mathrm{NH}_{2} \cdot \mathrm{COOH}$ & $10^{-8}$ & $0 \cdot 10 \pm 0 \cdot 05$ & $0 \cdot 27 \pm 0 \cdot 10$ \\
\hline L-Cystine & $\begin{array}{l}\text { S. } \mathrm{CH}_{2} \cdot \mathrm{CHNH}_{2} \cdot \mathrm{COOH} \\
\text { S. } \mathrm{CH}_{2} \cdot \mathrm{CHNH}_{2} \cdot \mathrm{COOH}\end{array}$ & $10^{-3}$ & $0 \cdot 78 \pm 0 \cdot 58$ & $0.72 \pm 0.43$ \\
\hline DL-Methionine & $\begin{array}{l}\mathrm{CH}_{3} \mathrm{~S} \cdot \mathrm{CH}_{2} \cdot \mathrm{CH}_{2} \\
\mathrm{CHNH}_{2} \cdot \mathrm{COOH}\end{array}$ & $10^{-3}$ & $0 \cdot 60 \pm 0 \cdot 27$ & $0 \cdot 15 \pm 0 \cdot 05$ \\
\hline Glutathione & 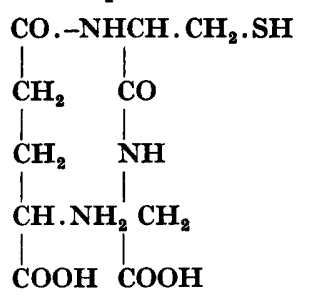 & $10^{-3}$ & $3 \cdot 10 \pm 0 \cdot 10$ & $0 \cdot 70 \pm 0 \cdot 32$ \\
\hline Ascorbic acid & & $10^{-2}$ & $5 \cdot 80 \pm 0 \cdot 50$ & $4.90 \pm 0 \cdot 25$ \\
\hline $\begin{array}{l}\text { Non-illuminated pe } \\
\text { medium. Control }\end{array}$ & & - & $5 \cdot 00 \pm 0 \cdot 00$ & - \\
\hline $\begin{array}{l}\text { Illuminated pea } \\
\text { medium. Control }\end{array}$ & & - & - & $0.15 \pm 0.08$ \\
\hline
\end{tabular}

Table 4. Growth of Phytophthora infestans as influenced by compounds in the presence, or absence, of ascorbic acid

$$
\begin{gathered}
\text { Compound } \\
\text { (all at } 10^{-8} \mathrm{M} \text { ) }
\end{gathered}
$$

Thioglycollic acid

Glycollic acid

L-Cysteine hydrochloride

DL-Alanine

Serine

L-Cysteine

DL-Methionine

Cystathionine

Glutathione (reduced)

None
Ascorbic acid
not added

$\mathbf{2} \cdot 10 *$

$\mathbf{1 \cdot 3 0}$

$2 \cdot 00$

$1 \cdot 00$

1.00

1.00

$1 \cdot 20$

$1 \cdot 10$

$1 \cdot 20$

$1 \cdot 20$
Ascorbic acid added

(1.0 g./1.)
$2 \cdot 20 *$

$1 \cdot 60$

$2 \cdot 80$

$1 \cdot 40$

$1 \cdot 40$

$\mathbf{2} \cdot 40$

$1 \cdot 50$

$1 \cdot 50$

$4 \cdot 40$

$1 \cdot 80$

L.S.D. two treatment values $0.35(P<0.001)$.

* Figures are the mean colony length $(\mathrm{cm}$.) of six replicates after 7 -day incubation. 


\section{The addition of sulphydryl compounds to a defined medium}

Compounds which contained a - SH group overcame the inhibitory effect of illuminated pea medium. Replacement of the-SH group with $\mathrm{H}$ or $\mathrm{OH}$, or oxidation to S-S, rendered these compounds ineffective. Ascorbic acid also overcame the inhibition, which indicated that perhaps Phytophthora infestans required the presence of reducing groups for growth. To investigate this point further the compounds listed in Table 4 were added to a basal medium which contained $(\%, w / v) \mathbf{K H}_{2} \mathbf{P O}_{4}$, $0.05 ; \mathrm{MgSO}_{4} .7 \mathrm{H}_{2} \mathrm{O}, 0.025 ; \mathrm{D}$-glucose, $2.5 ; \mathrm{L}$ - $\beta$-asparagine, $0.05 ; 1 \mathrm{ml}$. of the vitamin solution described by Pontecorvo (1953); distilled water. All compounds were added at a concentration of $10^{-3} \mathrm{M}$ and the $\mathrm{pH}$ was adjusted to $6 \cdot 0$ before autoclaving at $115^{\circ}$ for $10 \mathrm{~min}$. The effect of each compound on the growth of $P$. infestans was also tested in the presence of L-ascorbic acid $(1 \mathrm{~g} . / \mathrm{l}$.). Each tube was inoculated with a mycelial disc and colony length was measured after incubation for 7 days.

The results (Table 4) show that L-ascorbic acid, L-cysteine $\mathrm{HCl}$, and thioglycollic acid increased growth as compared with that on the control medium. This effect of L-cysteine $\mathrm{HCl}$ and thioglycollic acid on growth was lost by the replacement of the - SH group with either $\mathbf{H}$ or $\mathbf{O H}$. Glutathione, which was possibly altered during autoclaving (Isherwood, 1959), had no effect on growth when added alone, but in the presence of L-ascorbic acid it considerably increased growth (Pl. 1, fig. 2). $\mathrm{L}$-cystine, which contains sulphur in a form readily reduced to $-\mathrm{SH}$, increased growth only in the presence of ascorbic acid, but DL-methionine and DL-cystathionine, which contain sulphur in a form not easily reduced, had no effect on growth even in the presence of L-ascorbic acid.

Clearly, the interaction between - SH-containing compounds and ascorbic acid was dependent on the - SH compound used. Glutathione interacted strongly with L-ascorbic acid, but thioglycollic acid did not interact. Cysteine appeared to interact only slightly; to see whether this small interaction was the result of the concentrations used, a factorial experiment was made, using four concentrations (0.0, 0.01, 0.1 and $1.0 \mathrm{~g} . / 1$.) of both cysteine and ascorbic acid. The best growth was obtained with $0.1 \mathrm{~g}$. $/ 1$. L-cysteine $\mathrm{HCl}+\mathbf{1} \cdot 0 \mathrm{~g}$./1. L-ascorbic acid, which were approximately the concentrations used previously. On the other hand, when added together at $1.0 \mathrm{~g}$./l., L-ascorbic acid and L-cystiene $\mathrm{HCl}$ appeared to have a toxic effect on growth.

\section{DISCUSSION}

The evidence presented in this paper shows that the decreased growth of Phytophthora infestans on illuminated solid pea medium resulted not from a direct effect of light on the fungus, but from an indirect effect which caused an alteration of the medium. This alteration was complete after illumination for only $12 \mathrm{hr}$. Work by Bedford (1927), Woodrow, Bailey \& Fulmer (1927), Wyss et al. (1948) using ultraviolet radiation and Weinhold \& Hendrix (1963) using light also showed that effects of irradiation on micro-organisms resulted from an alteration of the organic media used. Whereas illuminated pea medium agar inhibited all the $\boldsymbol{P}$. infestans isolates tested, the majority of other fungi tested were unaffected; this suggests that perhaps the metabolism of $\boldsymbol{P}$. infestans is in some way different from that of even taxonomically similar species. Both Wyss et al. (1948) and Weinhold \& Hendrix (1963) 
reported that the type of inoculum had a marked effect on the magnitude of the inhibition caused by ultraviolet and light irradiation. In the present experiments zoospore germination was more sensitive to light-illuminated medium than was mycelial growth, suggesting that the effect of light was especially pronounced during the early stages of growth.

Work by Bedford (1927), Wyss et al. (1948) \& Weinhold \& Hendrix (1963) has indicated that the inhibitory effect of ultraviolet and light-irradiated medium may be caused by the presence of peroxides. Autoclaving did not remove the inhibitory effect of illuminated pea medium agar; and peroxides, therefore, seemed not to be the immediate cause of the decreased growth of Phytophthora infestans. However, the close association between peroxide formation and the appearance of the inhibitory effect suggested that peroxides were, in some way, responsible for the decreased growth.

Geise (1955) presented evidence which indicated a difference between hydrogen peroxide and ultraviolet irradiation in their effects on cell division in protozoa, and Bennett Clark, Wyss, \& Stone (1950) suggested that certain effects of ultraviolet irradiation might result from the inactivation of sulphydryl groups, and not from the formation of peroxides.

Not only did -SH-containing compounds and L-ascorbic acid overcome the inhibitory effect of illuminated pea medium but they also markedly increased the growth of Phytophthora infestans when added to a defined medium. The importance of the $-\mathrm{SH}$ group was emphasized by the fact that replacement of this group in sulphydryl compounds by $\mathrm{H}, \mathrm{OH}$, or -SS rendered the compounds ineffective. However, the fact that ascorbic acid also increased growth made it likely that it was the reducing properties of these compounds that were important (Hodgson, 1958). In view of the apparent requirement by $P$. infestans for reducing conditions, the difference in reducing potential between illuminated and non-illuminated medium might explain the effect of illumination, although the changes which caused this difference remained obscure.

Besides pointing the importance of reducing compounds in the metabolism of Phytophthora infestans this investigation has shown a point of practical value, namely that the addition of glutathione $0.3 \mathrm{~g} . / 1$. and ascorbic acid $1.0 \mathrm{~g} . / \mathrm{l}$. to the basal medium described earlier, considerably enhanced the growth of the fungus and brought it within the range of the best of the undefined media. Because these compounds are oxidized in light, cultures grown in this medium should be kept in darkness.

On the basis of the results presented in this paper, it may be argued that the growth of Phytophthora infestans within the potato depends on the maintenance of reducing conditions within host cells. Because the parasitism of $\boldsymbol{P}$. infestans resembles that of obligate parasites (Brown, 1955) it is perhaps of interest to note that Sahai \& Shaw (1961) detected increased amounts of ascorbic acid and glutathione on a rust-infected susceptible cereal variety. This caused a rise in the reducing potential (Kaul \& Shaw, 1960) which led Shaw (1963) to conclude that high reducing potentials were needed within host cells to enable growth and development of the rust fungus. 
Thanks are due to both Professor N. F. Robertson for his constant help and encouragement and to $\operatorname{Dr} A$. Fuchs, Wageningen, for his valuable advice during the preparation of the manuscript. This work was undertaken during the tenure of a Ministry of Agriculture, Fisheries and Food Studentship.

\section{REFERENCES}

ARNow, L. E. (1936). Effects produced by the irradiation of proteins and amino acids. Physiol. Rev. 16, 671.

BEDFORD, T. H. B. (1927). The nature of the action of ultraviolet on micro-organisms. Br. J. Exp. Path. 8, 437.

Bennett Clark, J., Wyss, O. \& Stone, W. S. (1950). Induction of mutation in Micrococcus pyogenes by chemical inactivation of sulphydryl groups. Nature, Lond. 166, 340.

Brown, W. (1955). On the physiology of parasitism in plants. Ann. appl. Biol. 43, 325.

Crosier, W. (1934). Studies in biology of Phytophthora infestans (Mont.) de Bary. Mem. Cornell Univ. Agric. Exp. Sta. no. 145.

Geise, A. C. (1955). Peroxide and ultraviolet radiation effects. Exp. Cell Res. 8, 369.

HaLl, A. M. (1959). The culture of Phytophthora infestans in artificial media. Trans. Br. mycol. Soc. 42, 15.

Hirst, J. M. (1953). Changes in atmospheric spore content: diurnal periodicity and the effects of weather. Trans. Br. mycol. Soc. 36, 375.

Hodgson, W. A. (1958). Growth of four races of Phytophthora infestans (Mont.) de Bary in synthetic media. Can. J. Pl. Sci. 38, 145.

Isherwood, F. A. (1959). Chemistry and biochemistry of glutathione. Biochem. Soc. Symp. 17, 3.

KaUd, R., \& Shaw, M. (1960). The physiology of host parasite relations. VI. Oxidationreduction changes in wheat leaf sap caused by rust infection. Can. J. Bot. 38, 399.

Koch, R. B., Stern, B. \& Ferrari, C. G. (1958). Linoleic acid and Trilinolein as substrates for Soybean lipoxidase(s). Archs. Biochem. Biophys. 78, 165.

LunDBerg, W. O. (1961). Autoxidation and Antioxidants. New York: J. Wiley and Sons, Inc.

Ponteconvo, G. (1953). Genetics of Aspergillus nidulans. Advanc. Genet. 5, 141.

SaraI, B. I. \& Shaw, M. (1961). The physiology of host parasite relations. VIII. Effects of rust infection on ascorbic acid and glutathione in wheat leaves. Can. J. Bot. 39, 1327.

Shaw, M. (1963). The physiology and host-parasite relations of the rusts. A. Rev. Phytopath. 1, 258.

WeINHold, A. R. \& Hendrix, F. F. (1963). Inhibition of fungi by culture media previously exposed to light. Phytopathology 53, 1280.

Woodrow, J. W., Barley, A. C. \& Fulmer, E. I. (1927). The effect of ultraviolet radiation upon yeast culture media. Pl. Physiol. 2, 171.

Woodward, G. E. (1933). The effect of ultraviolet, radium and X-ray irradiation on glutathione in pure solution. Biochem. J. 27, 1411.

Wyss, O., Bennett Clark, J., Hass, F. \& Stone, W. S. (1948). The role of peroxide in the biological effects of irradiated broth. J. Bact. 56, 51.

YARwOOD, C. E. (1937). The relation of light to the diurnal cycle of sporulation of certain downy mildews. J. Agric. Res. 54, 365.

\section{EXPLANATION OF PLATE}

Fig. 1. Inhibition caused by illuminated pea medium and the influence of inoculum source. $A$. Mycelial disc; B, $32.7 \times 10^{2}$ zoospores; C, 1.3 $\pm 10^{2}$ zoospores. U, Not illuminated.

Fig. 2. The effect of the sulphydryl group and ascorbic acid on the growth of Phytophthora infestans. A, Thioglycollic acid; B, L-cysteine HCl; C, L-cystine; D, glycollic acid; E, glutathione (reduced); X, L-ascorbic acid; Y, no ascorbic acid (control). 


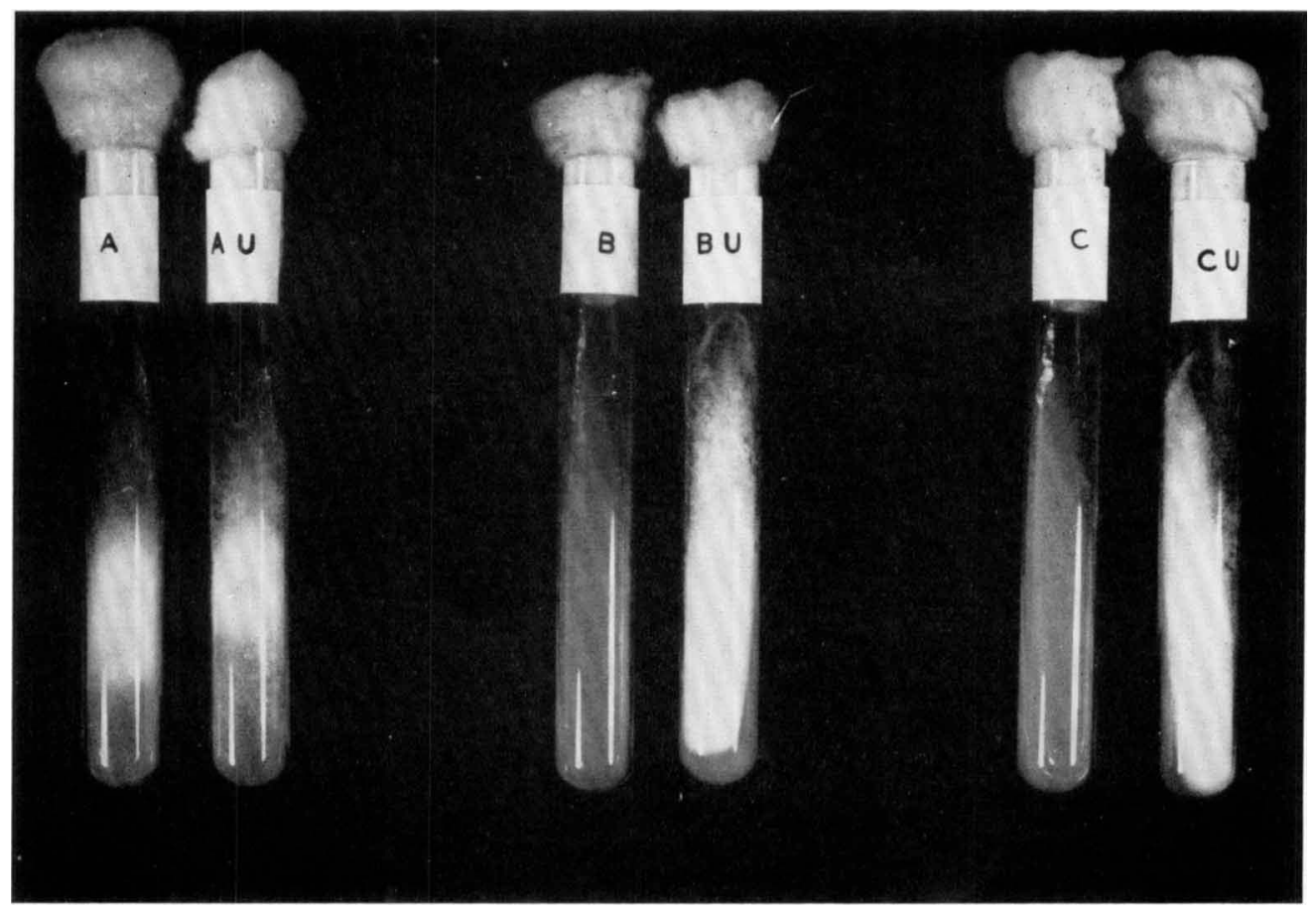

Fig. 1

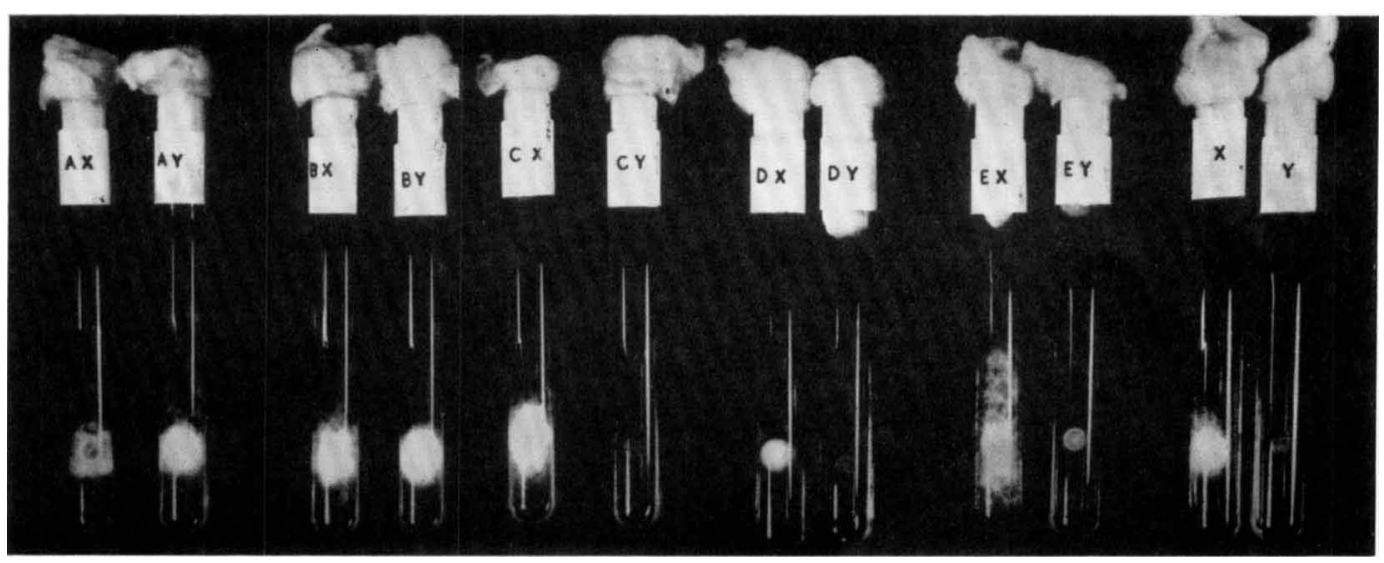

Fig. 2 